\title{
1821. México y Perú, la caída de los dos grandes virreinatos y la consumación de las independencias
}

\section{Mexico and Peru, the Fall of the Two Great Viceroyalties and the Consummation of the Independence}

En la década de 1820, los movimientos separatistas se impusieron en las principales capitales de la América española. Era el final de una larga guerra civil que se vivió con distinta intensidad según el lugar y el momento, resultado de la crisis y el colapso de las monarquías ibéricas, inicio de una nueva era en la que los antiguos espacios coloniales reformularon viejos y nuevos acuerdos, interpretados en clave de independencia y soberanía. La ruptura con la metrópoli parecía inminente conforme se afianzaban las victorias de Bolívar en Boyacá, Carabobo y Pasto, mientras que en el extremo sur del continente empezaban a formularse los primeros ensayos constitucionales, ya muy lejos de la égida española. Sólo los dos virreinatos más antiguos, el de Nueva España y el del Perú, se resistían a romper sus lazos con España; el primero, por estar estrechamente articulado con la metrópoli y muy lejos del alcance de los ejércitos libertadores; el otro, por las complejas fuerzas regionales que estaban en juego en el dilatado territorio peruano. De entrada, en el Perú hay que contar con la preminencia del Cuzco, la antigua capital del Tahuantinsuyu, frente al dominio de la capital virreinal, la ciudad de los Reyes, Lima.

Los dos virreinatos, el de la Nueva España y el del Perú, constituyeron los grandes centros del poder español en América. En principio sus estructuras socioeconómicas, demográficas y culturales podrían parecer semejantes; sin embargo, las diferencias son muy grandes: el oro y la plata peruana dominaron los primeros siglos coloniales, mientras que a fines del siglo XVII el boom de la plata mexicana vino a marcar la diferencia por su notable crecimiento y expansión en el siglo venidero. Algunos autores han subrayado también las diferencias en la implantación de la Iglesia secular, en la manera en que se reconoció la autoridad de los caciques y curacas por el poder colonial. Hay en estos terrenos un horizonte abierto para el diálogo entre los especialistas. 
Al examinar el curso de los acontecimientos políticos tras la crisis de la monarquía española, vemos que también el acontecer político de la época era muy distinto en los dos virreinatos. Cuando la monarquía borbónica se vio asediada por las tropas napoleónicas en 1808, las juntas del Ayuntamiento de la ciudad de México llevaron a un enfrentamiento radical entre criollos y peninsulares, en tanto el Perú mantuvo una política de concordia bajo el virrey Abascal. Y es que las grandes rebeliones indígenas del Perú, durante las últimas décadas del siglo XVIII, condicionaron fuertemente las reacciones que habrían de sobrevenir ante el colapso imperial: hubiese sido difícil pensar que los criollos peruanos armaran en ese momento un frente con las características del movimiento de Hidalgo. En poco más de una década, la historia de la guerra y del tránsito a la vida independiente no pudo ser más distinto.

A pesar del diferente recorrido que siguieron para llegar a la independencia, 1821 sería para ambos la fecha que la memoria histórica decidió fijar como punto de partida de una nueva era. El general San Martín llegó a Lima en 1821, proclamó la independencia el 28 de julio e intentó un acercamiento con la aristocracia limeña para tratar de instaurar una monarquía constitucional, mientras que Agustín de Iturbide formó una amplia coalición bajo el estandarte trigarante y entró a la ciudad de México, el 27 de septiembre de ese año, con la propuesta de traer a gobernar a Fernando VII o a un miembro de la familia real, según lo acordado en los Tratados de Córdoba. La idea de la monarquía no habría de sostenerse ni en México ni en el Perú en la convulsa década de 1820, pero fue popular en esos años. La separación definitiva de España no se consiguió en México sino hasta lograr la expulsión de los ejércitos realistas con la caída del fuerte de San Juan de Ulúa, en 1825; por su parte, las derrotas de Ayacucho, Tumusla y el Callao, entre diciembre de 1824 y enero de 1826, consolidaron el triunfo de la independencia peruana. Hay que recalcar que, en ambos casos, el triunfo militar se consiguió apenas en 1825 y 1826, algunos años después de la fecha en que se declararon las independencias.

No nos hallamos ante un periodo de investigación completamente desatendido. Desde tiempo atrás los historiadores se han interesado en explicar las causas y las consecuencias del derrumbe de los dos grandes virreinatos de la monarquía hispánica. A partir de mediados de los años setenta del siglo pasado, los estudios - en buena medida pioneros- de Brian R. Hamnett o Timothy E. Anna abrieron líneas de trabajo hasta ese momento poco exploradas y propusieron sugerentes hipótesis para contrastar 
lo sucedido en Perú y Nueva España (México), vinculando el proceso revolucionario con las resistencias al mismo y las dimensiones política, económica y social. Otras investigaciones posteriores han venido a reforzar, matizar o poner en cuestión lo señalado entonces por ambos autores. En la coyuntura de las conmemoraciones bicentenarias que tuvieron lugar entre 2008 y 2014 se asistió en México a una eclosión de eventos y congresos académicos; asimismo se contó con publicaciones cuyo momento álgido fue el doscientos aniversario del grito de Dolores, de 1810. Perú recordó también entonces algunas fechas significativas, como es el caso de la rebelión cuzqueña de 1814, pero lo cierto es que las miradas estaban puestas en el horizonte de 2021. Sin embargo, nadie se imaginaba a comienzos del año anterior que los preparativos de ese hito, tanto en un país como en el otro, se verían condicionados por una situación de emergencia sanitaria sin precedentes conocidos hasta ahora. A pesar de las dificultades que ello ha supuesto, se han seguido organizando diversas actividades, especialmente a través de las plataformas digitales. Las agendas de investigación se han volcado también a poner frente a frente los procesos peruano y mexicano, con publicaciones que buscan contrastar lo sucedido en ambos espacios desde distintas perspectivas de aproximación.

Sin duda, las independencias de 1821 deben ser entendidas en un contexto más global e interconectado. La revolución española de enero de 1820 supuso una conmoción en el ámbito internacional. El orden restaurado en 1814 por las potencias legitimistas de la Santa Alianza mostró sus límites y fue contestado por otros movimientos revolucionarios a ambos lados del Atlántico, ganando cada vez mayor importancia los sucesos que iban a desencadenarse en la América continental. Tanto en Perú como en México, los virreyes Pezuela y Apodaca trataron de contener en un primer momento la vuelta del liberalismo que implicaba la reposición de la constitución doceañista. La guerra actuó como un catalizador de las tensiones heredadas, agravó los problemas hacendísticos y menguó la capacidad defensiva de los gobiernos españoles. Los golpes de Estado militares que depusieron a ambos virreyes son una muestra de la crisis que entonces se atravesaba. Todo ello fue acompañado de una eclosión de la vida público-política, la reactivación de los procesos electorales y el aumento de las tensiones entre los territorios, con crecientes demandas de autogobierno por parte de los poderes locales y provinciales. También se debatió arduamente sobre la conveniencia o no de aplicar las medidas de reforma eclesiástica aprobadas por las cortes hispanas. Ciertamente, las motivaciones 
religiosas sirvieron para legitimar las acciones de los distintos bandos en conflicto. El avance de las tropas insurgentes se produjo en un tiempo de transformación y debate.

Los nuevos países tuvieron que sumar a las tensiones del momento muchos de los problemas no resueltos todavía. Por ello, el periodo de las independencias debe ser pensado también desde los dilemas que entonces se generaron, así como su posterior evolución y desarrollo. Los estados surgidos de la descomposición de las monarquías ibéricas tuvieron que hacer frente a cuestiones como la definición del marco constitucional, la construcción de la ciudadanía, la identidad de los pueblos indígenas, el papel de las fuerzas armadas y de las élites políticas, la búsqueda del reconocimiento internacional, los recurrentes ciclos de crisis fiscales, las dificultades de organización y de estructuración territorial, la apertura de nuevas rutas comerciales, la pugna entre secularización y confesionalidad o, entre otros, los discursos encontrados sobre las conmemoraciones y los espacios públicos. El conflicto entre los poderes legislativo y ejecutivo que arrancó en ese tiempo condicionó la gobernabilidad de las naciones y se prolongaría durante todo el siglo XIX.

A través de este dossier que conmemora los acontecimientos de 1821, hemos reunido un conjunto de miradas que abren un horizonte nuevo a los estudios de la independencia. En primer lugar, los ensayos toman distancia del relato tradicional y cuestionan muchos de los mitos historiográficos en torno a los orígenes de la nación al establecer serios contrapuntos a la narrativa liberal republicana y a la delimitación espacial de los estados nacionales. Los estudios se desenvuelven en el ámbito de la monarquía y en zonas regionales muy vastas: el territorio peruano comprende el Alto Perú (aunque éste ya no le pertenezca) y no se explica sin la interacción con Buenos Aires y Santiago; el imperio mexicano buscó abarcar la América septentrional entera y la fuerte articulación con la metrópoli explica las dificultades que entraña su separación. En segundo término, emergen nuevos actores políticos, como el hambre en una ciudad sitiada, o viejos actores que la historiografía no había estudiado con suficiente profundidad: tal es el caso del indio en la guerra, en las Cortes de Cádiz, en las medidas indigenistas de los dirigentes, en su relación con la comunidad y con el tributo puesto en cuestión durante el proceso de independencia. Éste y otros asuntos ponen en nuestras manos una invitación para hacer historia comparada, para atender a una historia conectada en la que las viejas articulaciones ceden a los incipientes impulsos que desembocan en un nuevo 
orden. En los ensayos podremos apreciar que el espacio peruano y el mexicano no son ajenos el uno del otro, ni entonces, ni ahora.

El dossier reúne seis artículos y una reseña crítica de historiadores peruanos, mexicanos y españoles; intenta contribuir a un diálogo abierto desde hace algunos años entre la historiografía peruana y la mexicanista, a través de la Pontificia Universidad Católica del Perú y la Universidad Nacional Autónoma de México. Agradecemos a la revista Estudios de Historia Moderna y Contemporánea de México el haber acogido esta propuesta para que el Instituto de Investigaciones Históricas participe de la celebración común y los proyectos universitarios de este año conmemorativo.

Ana Carolina Ibarra Instituto de Investigaciones Históricas, UNAM

Josep Escrig Rosa Becario Posdoctoral Instituto de Investigaciones Históricas, UNAM 